\title{
Understanding the Coexistence of Food Insecurity and Obesity
}

\author{
Edward A. Frongillo $\cdot$ Jennifer Bernal
}

Published online: 29 July 2014

(C) Springer Science + Business Media New York 2014

\begin{abstract}
Coexistence of food insecurity and obesity is expected given that both are consequences of economic and social disadvantage. Food insecurity and obesity are positively associated in adult women but not men. There is some evidence of association in adolescents, but mixed results for children. Distinct from adults, children experience cognitive, emotional, and physical awareness of food insecurity and take responsibility for it by participating in adult strategies, initiating their own strategies, and taking action to obtain additional food or money for food. Food insecurity is detrimental for children, being associated with behavior problems, disrupted social interactions, compromised school performance and attendance, poor dietary intake and physical activity, altered daily activities, and poor health. Some of these outcomes increase the risk of developing obesity. From life course, cumulative inequality, and developmental perspectives, child food insecurity may have long-term effects, including on risk of obesity. Pediatricians can help identify and respond to children who are food-insecure and at risk of obesity.
\end{abstract}

Keywords Children · Food insecurity · Obesity · Overweight · Life course · Cumulative inequality . Disadvantage $\cdot$ Child development

\footnotetext{
E. A. Frongillo ( $\square)$

Department of Health Promotion, Education, and Behavior, University of South Carolina, Discovery I, 915 Greene Street, Room 529, Columbia, SC 29208, USA

e-mail: efrongillo@sc.edu

\section{J. Bernal}

Departamento de Procesos Biológicos y Bioquímicos, Edif. Básico I, piso 2, Laboratorio de Evaluación Nutricional, Universidad Simón Bolívar, Caracas 1080, Venezuela e-mail: jbernal@usb.ve
}

\section{Introduction}

Across the globe, both adult and child overweight and obesity are increasing, with the rate of increase faster among children $[1,2]$. In low- and middle-income countries, early prevention of overweight and obesity have become concerns that coexist along with long-standing concerns about under-nutrition and its consequent impact on morbidity, mortality, and impaired child development [1]. In high-income countries, the dual burden of inadequate nutrition and overweight and obesity has been highlighted for some time.

Over the past 20 years, the coexistence of household food insecurity and obesity has been labeled a paradox, but we now know that there is nothing paradoxical about this coexistence [3]. When this label was introduced, there was little knowledge of the causes, mechanisms, and consequences of household food insecurity. When the US national nutrition monitoring system began, the conceptual framework that was used depicted that poverty resulted in household food insecurity, leading to poor dietary quality and quantity, under-nutrition, and poor health [4]. Spurred in large part by the development and use of questionnaire instruments to assess food insecurity through queries about individuals' experiences and perceptions of food insecurity and behavioral responses to it, substantial new knowledge about food insecurity has been gained, leading to a more comprehensive conceptual framework [4]. Both in-depth qualitative and quantitative studies in the US and other countries contributed to this new knowledge [3].

Household food insecurity occurs when an individual or set of individuals experiences uncertainty about future food availability and access, insufficiency in the amount and kind of food required for health, or the need to use socially unacceptable ways to acquire food [4]. Several closely 
linked consequences are potentially part of the experience of food insecurity. Hunger and malnutrition (i.e., undernutrition or obesity) may be experienced as part of food insecurity. Closely linked social and psychological consequences of food insecurity may include worry and anxiety; feeling alienation, deprivation, and distress; and adverse family and social interactions [4]. For example, household food insecurity in Burkina Faso is closely linked with concern, worries, and anxiety, which eventually result in weight and sleep loss; feelings of alienation (e.g., shame) and deprivation (e.g., guilt); and disrupted household cohesion leading to disputes and difficulties in keeping children at home [5]. That is, closely linked consequences of food insecurity occur through both nutritional and nonnutritional pathways [4]. Furthermore, because food insecurity is a powerful form of economic and social disadvantage, and food needs may compete with other needs, food insecurity leads to changes in behaviors, some involving trade-offs among needs. People experiencing food insecurity may reduce investments in productive assets, education, and children; avoid risks regarding means of production or earning; and emphasize survival over other goals by migrating or diversifying livelihood strategies [4]. Therefore, there are many potential outcomes related to food insecurity.

\section{Knowledge About Coexistence of Food Insecurity and Obesity}

Recent reviews of the association between food insecurity and obesity have reported mixed findings [6•, 7, 8, 9••]. Overall, these reviews suggest that food insecurity and obesity are positively associated in adult women but not in adult men. There is some evidence of association in adolescents, but mixed results for children. Few studies support a linear relationship between food insecurity and weight outcomes. Furthermore, the association between food insecurity and obesity is modified (in addition to gender) by marital status, stressors, and participation in food assistance programs. These reviews have also pointed to methodological needs in future research, including the use of longitudinal studies rather than cross-sectional studies, development of tools to distinguish acute and chronic food insecurity, and greater inclusion of food security measurement tools in regional and local studies.

More recent studies have shed further light on possible mechanisms for how food insecurity and obesity might be linked. Obesity has been discussed as a physical expression of the vulnerabilities that arise from the intersection of gender differences in childcare expectations and poverty [10]. Related to this, deprivation and restricted food choice that are associated with low socioeconomic status enhance food reinforcement (i.e., a positive feedback loop in which food eaten in response to deprivation is eaten more frequently), increasing risk of obesity [11]. Greater concern about future overweight in infants leading to controlling feeding styles represents a potential mechanism by which food insecurity could be related to obesity in children [12]. It is possible but unknown if children reflect maternal stress and manifest it in overeating, or if children model maternal eating as a coping mechanism.

The association of food insecurity and obesity is likely modified by some additional factors, at least in some contexts. For example, children of underweight, overweight, or obese (i.e., not normal weight) mothers had greater odds of obesity with persistent household food insecurity compared to those with persistent household food security [13]. An increase in maternal stressors (e.g., unemployment and disability) amplified food-insecure adolescent's probability of being overweight or obese [14]. Dietary restraint is another potential modifier; women with low dietary restraint and experiencing marginal food insecurity may be at high risk of weight gain [15].

\section{Food Assistance, Food Insecurity, and Obesity}

Concern that participating in food assistance programs might exacerbate obesity goes back to at least 1974 [16]. Long-term participation in the Supplemental Nutrition Assistance Program (SNAP) may increase risk for excess weight gain [7]. The evidence that this may occur is limited and is primarily based on observational studies. For example, food assistance program participation was associated with increased body size in food-insecure youth but not food-secure youth [17]. Participants in emergency food assistance programs with food insecurity were more likely to be overweight or obese compared with participants with food security (80.5 vs. $61.5 \%$, respectively) [18]. The use of emergency food assistance may help minimize food insecurity while providing access to foods with varying nutritional quality that may be associated with increased risk of overweight and obesity. The prevailing view is that, if participation in food assistance programs exacerbates obesity, the effect is small [6•].

One randomized study recently has been done of the effect of a program in Mexico which provided poor rural households with cash or in-kind transfers on the body weight of adult women [19•]. Women receiving a food basket or cash had significantly increased weight (70 and $53 \%$ increases in weight gain, respectively) compared to the control group over 23 months. The greatest effect was found in the already obese women, with no effect among women who were not already overweight or obese. These results highlight the need to provide cost-effective health 
promotion to complement food assistance to help participants choose healthy foods that improve the nutritional status of all family members. Health promotion efforts should be targeted to those most at risk and who could most benefit.

Another recent study using US national data and modeling techniques examined two potential modifications to the USDA's Supplemental Nutrition Assistance Program (SNAP) to promote healthy food choices [20]. One potential modification is to ban use of SNAP dollars to buy sugar-sweetened beverages and the other is a subsidy in which for every SNAP dollar spent on fruit and vegetables, thirty cents are credited back to participants' SNAP benefit cards. The authors found that the first modification (i.e., ban on purchases of sugar-sweetened beverages) would significantly reduce prevalence of obesity and incidence of type 2 diabetes, especially among adults and in some racial/ethnic groups. The second modification would not significantly affect obesity and type 2 diabetes, but could increase the proportion of SNAP participants meeting guidelines for vegetable and fruit consumption.

\section{Child Experiences of Food Insecurity and Obesity}

Household food insecurity substantially affects children. Food insecurity is associated with children's behavior problems, disrupted social interactions, compromised school performance $[4,21]$, poor dietary intake and lower physical activity [22], altered daily activities and school absenteeism [23], and poor health [24]. Some of these outcomes could increase the risk of developing obesity. For example, a food-insecure child could have more access to foods of low quality and high energy density that are ready to eat, especially if the parents are not at home. In Venezuela, food-insecure children more frequently ate salty crackers and less frequently ate papaya, banana, and salad than food-secure children [23]. Children with food insecurity watch more television to forget they are hungry [25•]; watching more television may increase risk of obesity [26, 27].

Children's experiences of food insecurity are distinct from those of adults. As explained below, children experience cognitive, emotional, and physical awareness of food insecurity and take responsibility for it by participating in adult strategies, initiating their own strategies, and generating resources $\left[25^{\bullet}, 28 \bullet \cdot\right.$. Cognitive awareness refers to children knowing that food is scarce and how their family manages food problems. Emotional awareness refers to feelings of worry, sadness, or anger that are linked to food insecurity. Physical awareness refers to physical feelings of hunger, pain, tiredness, and weakness that are linked to insufficient food. Participation refers to going along with adult strategies for managing resources for food. Initiation of strategies refers to actions that the child takes to stretch existing resources for food. Generation of resources refers to action taken to obtain additional food or money to obtain food. In low-income populations, children frequently experience each of these aspects of food insecurity $[23,29]$.

These child experiences of food insecurity have potential implications for development of obesity. Emotional awareness of food insecurity could be related with obesity. In Rhode Island, greater maternal depressive symptoms were associated with negative family food behaviors, but not with the weight of preschool children [30]. Emotional feeding behavior (i.e., offering food to soothe a child's negative emotions) was the characteristics of parents most related to child emotional eating; treatment of overweight children who engage in emotional eating may be improved by targeting parental feeding practices [31]. Some strategies used by children in response to food insecurity may increase their access to affordable foods, but also ones with low quality. Feelings of tiredness and weakness may relate to decreased motivation or energy to engage in physical activity.

Parents try to protect children from food insecurity, but often do not succeed, and children try to protect their parents and siblings [25•, 28••]. Parents have many goals for children, including security and certainty, safety, nutrition and health, education, emotional and social development, family cohesion, and belonging and acceptance. Parents have to make trade-offs among these goals, particularly when there is social disadvantage. For example, if the only way a parent can feasibly help a child feel normal (i.e., belongs) is to take the child to a fast-food restaurant, then belonging and acceptance is being tradedoff against nutrition and health. This pattern over time could increase the risk of obesity among the economically and socially disadvantaged.

\section{Food Environment, Food Insecurity, and Obesity}

Industrial food processing is part of the food environment, playing a role in shaping global food systems, supplies, and thus dietary patterns worldwide [32]. The food environment has evolved along with the pandemic of overweight and obesity, and the influence of the food environment remains underappreciated. The food supplies of highincome countries, urban settings in low- and middleincome countries, and even rural areas of many middleincome countries increasingly consist of food products that are mass-produced, branded, processed, and heavily advertised. These industrial products include mass-produced and inexpensive breads, buns, cakes, breakfast 
cereals, cookies and biscuits, candies, sweetened fruit preserves, syrups, condensed milk, soft drinks and other beverages with high sugar content, meat, lard, cheese, and other dairy products. Because of affordable prices, these ready-to-eat and convenient foods and drinks are selectively eaten by the socially disadvantaged [33-35]. Also, some of these foods may be eaten in response to the stress that disadvantaged people experience, reflecting differences in personal and behavioral factors between overweight or obese and lean or normal women. For example, one obese woman participating in a focus group of lowincome women of mixed race/ethnicity in urban Minnesota reported: "I get depressed with not having a job or income. Like me being young and being by myself taking care of my kids, I go straight to foods that comfort me" [36]. Caregivers who were food-insecure compared with those food-secure reported significantly more foods in the home that might promote obesity, more frozen foods that were microwavable or quick to cook, and less healthful foods in the kitchen [37].

Taxes on unhealthy foods and food constituents such as sugar have been proposed to prevent excess consumption of foods with high energy density and obesity. High taxes would have the greatest impact on adolescents, persons of low socioeconomic status, and populations at risk for obesity [34]. In the US, statistically significant associations were found between prices of food and restaurants and weight; the associations were small in magnitude, but were larger for groups with low socioeconomic status and at risk for overweight or obesity [33]. In Mexico, caloric sodas are one of the top beverages consumed; a $10 \%$ tax on high sugar-sweetened beverages has been enacted [35]. Modeling of the potential effect of taxes on food in Australia showed effectiveness and cost-saving, with reduced weight, disease, and cost [38]. Use of tax policy to reduce consumption of unhealthy food and prevent obesity is new and largely untested. Such policies may have a differential effect on low-income populations that have high prevalence of food insecurity. How these policies will be received and how they will affect children is not well understood.

\section{Life Course and Cumulative Inequality Perspectives}

Life course theory provides an important perspective through which we might understand the association of food insecurity and obesity [39]. Life course theory posits that what happens during one moment in life influences what happens later. It emphasizes life transitions, trajectories of actions, and timing of life events in relationship to historical changes and present contexts.
There have been no true studies of the association of food insecurity and obesity from childhood to adulthood from a life course perspective. Study of poverty and obesity provides an example, however, of how food insecurity might operate over the life course. Poverty or welfare receipt in childhood is associated with adult obesity for females but not males, whereas other measures of socioeconomic disadvantage (e.g., neighborhood poverty, low parental education) are associated with obesity in both males and females [40]. Poverty may impact female obesity through the mediating effects of physical inactivity, inadequate sleep, skipping breakfast, and certain forms of parental monitoring.

There have been a few studies of physical activity and obesity from a life course perspective. Early physical activity promotes lower prevalence of chronic diseases in adulthood [41]. In Canada, body mass index, but not physical activity, tracked well over 22 years from child to adult [42]. In Norway, childhood physical fitness was inversely associated with obesity in early adulthood, but this association diminished markedly into middle age [43]. The relevance of these studies is potentially enhanced with findings that food insecurity reported by Venezuelan children is associated with altered patterns of daily activities (particularly work activities) and physical activity [23], and that household food insecurity reported by US adults is associated with lower physical activity in both adults and children [44].

Longitudinal and qualitative studies are needed, but thoughtful cross-sectional studies may also be useful. For example, among Mexican mothers with low schooling (i.e., not completed primary school), greater wealth was not associated with greater child height, but was associated with a greater maternal weight [45]. Among mothers with higher schooling, greater wealth was associated with greater child height, but not with maternal weight. That is, maternal schooling prevented the negative association of wealth with maternal weight. In another example, analysis with cross-sectional data in Brazil has clarified that household food insecurity is associated with obesity differently over the life course in females [46]. Food insecurity was not associated with obesity in children, but was associated with obesity in female adolescents and adults.

A longitudinal analysis in US children illustrates how taking a life course perspective may shed light on how food insecurity is associated with obesity over time [47]. US children were followed from kindergarten to eighth grade, with measurements at five time points. Female children living in a food-insecure household during kindergarten had a somewhat smaller body mass index compared to female children in food-secure households. Over time from kindergarten and eighth grade, female food-insecure children had greater gains in body mass index, with the result 
that in eighth grade, body mass index was slightly higher in food-insecure females compared to food-secure females. Thus, food insecurity modestly but significantly was associated with greater gains in body mass index in female children, insight that could not have been gained by a study at just one point in time.

Related to life course theory is cumulative inequality theory, which posits that advantage established in early life results in greater accumulation of opportunities and resources that put already advantaged individuals in a better position to delay the onset of illness. As a result, health disparities between advantaged and disadvantaged groups widen as individuals age. An example of cumulative inequality theory as applied to development of obesity is a longitudinal study that showed that there are large differences in body mass index in the US among whites, blacks, and Hispanics from ages 16 to 44 years [39]. Within each racial/ethnic group, study participants with fewer years of schooling had higher body mass index than participants with more years of schooling. When the differentiation was made by the years of schooling of the participants' mothers, however, the differences in body mass index were markedly greater. These results suggest that the cumulative effect of inequity represented by mothers' years of school had a large effect on the body mass index of the offspring.

These perspectives about the life course and cumulative inequality over time fit with the recently elaborated unified theory of child development [48]. This theory combines models for personal change over time, the expanding influence of context as a child becomes older, and transactional as well as self-regulation. Transactional regulation means the "continuous dynamic interactions of the child and the experience provided by his or her social settings." Food insecurity is a salient feature of the social setting of many disadvantaged children.

\section{Needs for Future Research}

Several questions are important to answer in future research. First, we need to understand better the mechanisms and consequences of child experiences of food insecurity (and effects in childhood) for later well-being (i.e., on food choices, economic welfare, and physical and mental health). Second, why and how do these consequences occur, i.e., what are mediators and modifiers? Third, are effects of child experiences of food insecurity cumulative? Fourth, why are food insecurity and obesity associated for women but not men? Does this gender difference originate from childhood, how does the gender difference relate to social norms and different contexts, and what is the relative contribution of weight gain from pregnancy? Addressing these questions about gender differences will spur further thinking on the likely important mechanisms. Fifth, particularly important from a policy perspective, how can food assistance contribute to preventing both food insecurity and its potential consequences, including obesity?

\section{Conclusions}

Food insecurity is detrimental for children, and child experiences of food insecurity may have long-term adverse effects. Economic and social disadvantage results in both food insecurity and obesity. The coexistence of food insecurity and obesity is well founded in understanding that people living in poverty are disadvantaged in many ways, and it is a myth that this coexistence is paradoxical [3]. From both scientific and policy perspectives, it is not important to know if food insecurity causes obesity contemporaneously. Both food insecurity and obesity are consequences of disadvantage that should be prevented [49]. An important policy concern for the association of food insecurity and obesity is that food assistance may be seen as not needed and as exacerbating the association [6•]. Food assistance is an important aid for families and children to ensure adequate food, an aid that is responsive to changing economic conditions [50]. We do not know how the decision to accept food assistance or to receive it affects uncertainty (with its associated anxiety and worry) and other emotional mechanisms by which food insecurity may be linked to obesity. Development of strategies for having food assistance contribute to improving the nutritional quality of the food consumed is also important in the context of helping the entire population achieve healthy weight, regular physical activity, and obesity prevention.

Parents, who provide the immediate social environment for particularly young children, have an important role to play as caregivers to mitigate effects of food insecurity on children and to promote healthy weight. The presence of a caregiver whenever a child eats, not just at meals, and better food resource management skills by parents may promote healthy weight in low-income preschoolers [29]. Pediatricians, school personnel, social workers, coaches, and other professionals in contact with children also can play a role. Assessment of child food insecurity by professionals might provide crucial information to alert them to food-related problems experienced by the child. Assessment should use children's own reporting of their experiences. A small set of items assessing child awareness of and responses to food insecurity has proven accurate [29] and is available from the first author. These items may provide information that is useful for determining effective 
actions, the choice of which might depend on the aspects of child food insecurity experienced.

\section{Disclosure Edward A. Frongillo and Jennifer Bernal}

Human and Animal Rights and Informed Consent This article does not contain any studies with human or animal subjects performed by any of the authors.

\section{References}

Papers of particular interest, published recently, have been highlighted as:

- Of importance

- Of major importance

1. Black RE, Victora CG, Walker SP, Bhutta ZA, Christian P, de Onis M, Ezzati M, Grantham-McGregor S, Katz J, Martorell R, et al. Maternal and child undernutrition and overweight in lowincome and middle-income countries. Lancet. 2013;382(9890):427-51. doi:10.1016/S0140-6736(13)60937-X.

2. Popkin BM, Conde W, Hou N, Monteiro C. Is there a lag globally in overweight trends for children compared with adults? Obesity. 2006;14(10):1846-53.

3. Frongillo EA. Confronting myths about household food insecurity and excess weight. Cad Saude Publica. 2013;29:229-30.

4. National Research Council. Food insecurity and hunger in the United States: an assessment of the measure. Panel to review the U.S. Department of Agriculture's measurement of food insecurity and hunger. In: Wunderlich GS, Norwood JL, editors. Committee on National Statistics, Division of Behavioral and Social Sciences and Education. Washington, DC: The National Academies Press; 2006

5. Nanama S, Frongillo EA. Altered social cohesion and adverse psychological experiences with chronic food insecurity in the non-market economy and complex households of Burkina Faso. Soc Sci Med. 2012;74:444-51.

6. - Institute of Medicine. Hunger and obesity: understanding a food insecurity paradigm: workshop summary. Washington: The National Academies Press; 2011. Provides a comprehensive discussion by experts from many disciplines of issues related to the coexistence of food insecurity and obesity.

7. Larson NI, Story MT. Food insecurity and weight status among US children and families: a review of the literature. Am J Prev Med. 2011;40(2):166-73.

8. Eisenmann JC, Gundersen C, Lohman BJ, Garasky S, Stewart $\mathrm{SD}$. Is food insecurity related to overweight and obesity in children and adolescents? A summary of studies, 1995-2009. Obes Rev. 2011;12:73-83.

9. •- Franklin B, Jones A, Love D, Puckett S, Macklin J, WhiteMeans S. Exploring mediators of food insecurity and obesity: a review of recent literature. J Community Health. 2012; 37(1):253-264. Reviews evidence for the association between food insecurity and obesity.

10. Martin MA, Lippert AM. Feeding her children, but risking her health: the intersection of gender, household food insecurity and obesity. Soc Sci Med. 2012;74:e1754-64.

11. Lin H, Carr KA, Fletcher KD, Epstein LH. Food reinforcement partially mediates the effect of socioeconomic status on body mass index. Obesity. 2013;21:1307-12.

12. Gross RS, Mendelsohn AL, Fierman AH, Racine AD, Messito MJ. Food insecurity and obesogenic maternal infant feeding styles and practices in low-income families. Pediatrics. 2012;130(2):254-61.

13. Metallinos-Katsaras E, Must A, Gorman K. A longitudinal study of food insecurity on obesity in preschool children. J Acad Nutr Diet. 2012;112:1949-58.

14. Lohman BJ, Stewart S, Gundersen C, Garasky S, Eisenmann JC. Adolescent overweight and obesity: links to food insecurity and individual, maternal, and family stressors. J Adolesc Health. 2009;45:230-7.

15. Laraia B, Epel E, Siega-Riz AM. Food insecurity with past experience of restrained eating is a recipe for increased gestational weight gain. Appetite. 2013;65:178-84.

16. Frongillo EA. Understanding obesity and program participation in the context of poverty and food insecurity. $J$ Nutr. 2003;133:2117-8.

17. Kohn MJ, Bell JF, Grow HM, Chan G. Food insecurity, food assistance and weight status in US youth: new evidence from NHANES 2007-2008. Pediatr Obes. 2014;9(2):155-66.

18. Walker RE, Kawachi I. Use of concept mapping to explore the influence of food security on food buying practices. J Acad Nutr Diet. 2012;112:711-7.

19. • Leroy JL, Gadsden P, González de Cossío T, Gertler P. Cash and in-kind transfers lead to excess weight gain in a population of women with a high prevalence of overweight in rural Mexico. J Nutr 2013;143:378-383. Demonstrates effects of a food and cash transfer program on obesity in women from a randomized study.

20. Basu S, Seligman HK, Gardner C, Bhattachary J. Ending SNAP subsidies for sugar-sweetened beverages could reduce obesity and type 2 diabetes. Health Aff. 2014;33(6):1032-9.

21. Jyoti D, Frongillo EA, Jones S. Food insecurity affects school children's academic performance, weight gain, and social skills. J Nutr. 2005;135:2831-9.

22. Fram MS, Frongillo EA, Fishbein EM, Burke MP. Roles for schools and school social workers in improving child food security. Child Schools. 2014. doi:10.1093/cs/cdu018.

23. Bernal IJ. Inseguridad alimentaria y hambre en niños: diseño y validación de instrumento para su estudio [dissertation]. Caracas, DC: Universidad Simón Bolívar; 2010.

24. Casey PH, Szeto KL, Robbins JM, Stuff JE, Connell C, Gossett JM, Simpson PM. Child health-related quality of life and household food security. Arch Pediat Adol Med. 2005;159(1):51-6.

25. - Bernal J, Frongillo EA, Herrera H, Rivera J. Children live, feel, and respond to experiences of food insecurity that compromise their development and weight status in peri-urban Venezuela. J Nutr 2012;142:1343-1349. Provides insight into the experiences of children living with food insecurity based on qualitative interviews with children.

26. Jones BL, Fiese BH, The Strong Kids Team. Parent routines, child routines, and family demographics associated with obesity in parents and preschool-aged children. Front Psychol. 2014;5:374. doi:10.3389/fpsyg.2014.00374.

27. Laurson KR, Lee JA, Gentile DA, Walsh DA, Eisenmann JC. Concurrent associations between physical activity, screen time, and sleep duration with childhood obesity. ISRN Obes. 2014;2014:204540. doi:10.1155/2014/204540.

28. •• Fram MS, Frongillo EA, Jones SJ, Williams RC, Burke MP, DeLoach KP, Blake CE. Children are aware of food insecurity and take responsibility for managing food resources. J Nutr 2011;141:1114-1119. Presents a conceptual framework about child experiences of food insecurity and how they respond to it based on qualitative interviews with children.

29. Fram MF, Frongillo EA, Draper CL, Fishbein EM. Development and validation of a child-report assessment of child food insecurity and comparison to parent-report assessment. J Hunger Environ Nutr. 2013;8:128-45. 
30. McCurdy K, Gorman KS, Kisler T, Metallinos-Katsaras E. Associations between family food behaviors, maternal depression, and child weight among low-income children. Appetite. 2014;79:97-105.

31. Braden A, Rhee K, Peterson CB, Rydell SA, Zucker N, Boutelle K. Associations between child emotional eating and general parenting style, feeding practices, and parent psychopathology. Appetite. 2014;80:35-40.

32. Moubarac JC, Parra DC, Cannon G, Monteiro CA. Food classification systems based on food processing: significance and implications for policies and actions: a systematic literature review and assessment. Curr Obes Rep. 2014;3(2):256-72. doi:10.1007/s13679-014-0092-0.

33. Powell LM, Chaloupka FJ. Food prices and obesity: evidence and policy implications for taxes and subsidies. Milbank Q. 2009;87(1):229-57.

34. Franck C, Grandi SM, Eisenberg MJ. Taxing junk food to counter obesity. Am J Public Health. 2013;103(11):1949-53.

35. Stern D, Piernas C, Barquera S, Rivera JA, Popkin BM. Caloric beverages were major sources of energy among children and adults in Mexico, 1999-2012. J Nutr. 2014;144:949-56.

36. Dressler H, Smith C. Health and eating behavior differs between lean/ normal and overweight/obese low-income women living in foodinsecure environments. Am J Health Promot. 2013;27(6):358-65.

37. Nackers LM, Appelhans BM. Food insecurity is linked to a food environment promoting obesity in households with children. J Nutr Educ Behav. 2013;45:780-4.

38. Sacks G, Veerman JL, Moodie M, Swinburn B. 'Traffic-light' nutrition labelling and 'junk-food' tax: a modelled comparison of costeffectiveness for obesity prevention. Int J Obes. 2011;35:1001-9.

39. Walsemann KM, Ailshire J, Bell BA, Frongillo EA. BMI trajectories from adolescence to midlife: differential effects of parental and respondent education by race/ethnicity and gender. Ethn Health. 2012;17(4):337-62. doi:10.1080/13557858.2011.

40. Lee H, Harris KM, Gordon-Larsen P. Life course perspectives on the links between poverty and obesity during the transition to young adulthood. Popul Res Policy Rev. 2009;28:505-32.
41. Fernandes RA, Zanesco A. Early physical activity promotes lower prevalence of chronic diseases in adulthood. Hypertens Res. 2010;33:926-31.

42. Herman KM, Craig CL, Gauvin L, Katzmarzyk PT. Tracking of obesity and physical activity from childhood to adulthood: the physical activity longitudinal study. Int J Pediatr Obes. 2009;4:281-8.

43. Kvaavik E, Klepp KI, Tell GS, Meyer HE, Batty GD. Physical fitness and physical activity at age 13 years as predictors of cardiovascular disease risk factors at ages 15, 25, 33, and 40 years: extended follow-up of the Oslo Youth Study. Pediatrics. 2009;123:80-6.

44. To QG. Food insecurity and physical activity among US populations [thesis]. Columbia, SC: University of South Carolina; 2014.

45. Leroy JL, Habicht JP, González de Cossío T, Ruel M. Maternal education mitigates the negative effects of higher income on the double burden of child stunting and maternal overweight: crosssectional study. J Nutr. 2014;144(5):765-70.

46. Schlüssel MM, Moura da Silva AA, Pérez-Escamilla R, Kac G. Household food insecurity and excess weight/obesity among Brazilian women and children: a life-course approach. Cad Saude Publica. 2013;29(2):219-26.

47. Burke MP, Frongillo EA, Jones SJ, Bell BA. Household food insecurity affects school children's growth in body mass index. FASEB J. 2012;26(28):2.

48. Sameroff A. A unified theory of development: a dialectic integration of nature and nurture. Child Dev. 2010;81(1):6-22.

49. Gundersen C, Garasky S, Lohman BJ. Food insecurity is not associated with childhood obesity as assessed using multiple measures of obesity. J Nutr. 2009;139:1173-8.

50. Rosenbaum D. SNAP is effective and efficient. Washington, DC: Center on Budget and Policy Priorities, 2013. http://www.cbpp. org/files/7-23-10fa.pdf. Accessed 6 June 2014. 